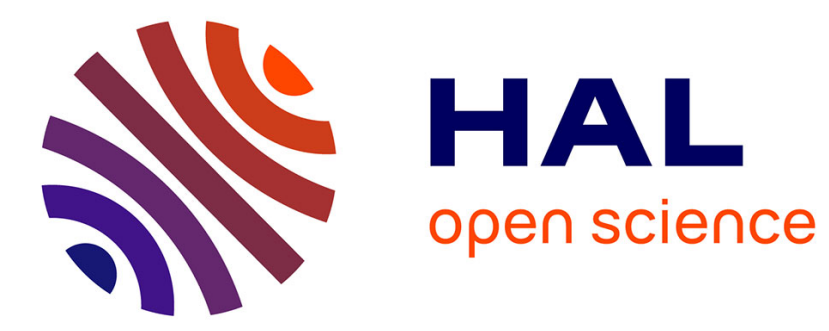

\title{
Implications for Deriving Regional Fossil Fuel CO 2 Estimates from Atmospheric Observations in a Hot Spot of Nuclear Power Plant 14 CO 2 Emissions
}

Felix Vogel, Ingeborg Levin, Doug Worthy

\section{- To cite this version:}

Felix Vogel, Ingeborg Levin, Doug Worthy. Implications for Deriving Regional Fossil Fuel CO 2 Estimates from Atmospheric Observations in a Hot Spot of Nuclear Power Plant 14 CO 2 Emissions. Radiocarbon, 2016, 55 (3), pp.1556-1572. 10.1017/S0033822200048487 . hal-03210283

\section{HAL Id: hal-03210283 \\ https://hal.science/hal-03210283}

Submitted on 4 Jun 2021

HAL is a multi-disciplinary open access archive for the deposit and dissemination of scientific research documents, whether they are published or not. The documents may come from teaching and research institutions in France or abroad, or from public or private research centers.
L'archive ouverte pluridisciplinaire HAL, est destinée au dépôt et à la diffusion de documents scientifiques de niveau recherche, publiés ou non, émanant des établissements d'enseignement et de recherche français ou étrangers, des laboratoires publics ou privés. 


\title{
IMPLICATIONS FOR DERIVING REGIONAL FOSSIL FUEL $\mathrm{CO}_{2}$ ESTIMATES FROM ATMOSPHERIC OBSERVATIONS IN A HOT SPOT OF NUCLEAR POWER PLANT ${ }^{14} \mathrm{CO}_{2}$ EMISSIONS
}

\author{
Felix R Vogel ${ }^{1,2} \bullet$ Ingeborg Levin ${ }^{3}$ Doug E J Worthy ${ }^{1}$
}

\begin{abstract}
Using $\square^{14} \mathrm{C}$ observations to infer the local concentration excess of $\mathrm{CO}_{2}$ due to the burning of fossil fuels $\left(\square \mathrm{FFCO}_{2}\right)$ is a promising technique to monitor anthropogenic $\mathrm{CO}_{2}$ emissions. A recent study showed that ${ }^{14} \mathrm{CO}_{2}$ emissions from the nuclear industry can significantly alter the local atmospheric ${ }^{14} \mathrm{CO}_{2}$ concentration and thus mask the $\square^{14} \mathrm{C}$ depletion due to $\mathrm{ZFFCO}_{2}$. In this study, we investigate the relevance of this effect for the vicinity of Toronto, Canada, a hot spot of anthropogenic ${ }^{14} \mathrm{CO}_{2}$ emissions. Comparing the measured emissions from local power plants to a global emission inventory highlighted significant deviations on interannual timescales. Although the previously assumed emission factor of 1.6 $\mathrm{TBq}(\mathrm{GWa})^{-1}$ agrees with the observed long-term average for all CANDU reactors of $1.50 \pm 0.18 \mathrm{TBq}(\mathrm{GWa})^{-1}$. This powerbased parameterization neglects the different emission ratios for individual reactors, which range from $3.4 \pm 0.82$ to $0.65 \pm$ $0.09 \mathrm{TBq}(\mathrm{GWa})^{-1}$. This causes a mean difference of $-14 \%$ in ${ }^{14} \mathrm{CO}_{2}$ concentrations in our simulations at our observational site in Egbert, Canada. On an annual time basis, this additional ${ }^{14} \mathrm{CO}_{2}$ masks the equivalent of $27-82 \%$ of the total annual $\mathrm{FFCO}_{2}$ offset. A pseudo-data experiment suggests that the interannual variability in the masked fraction may cause spurious trends in the $\mathrm{ZFFCO}_{2}$ estimates of the order of 30\% from 2006-2010. In addition, a comparison of the modeled $\square^{14} \mathrm{C}$ levels with our observational time series from 2008-2010 underlines that incorporating the best available ${ }^{14} \mathrm{CO}_{2}$ emissions significantly increases the agreement. There were also short periods with significant observed $\square^{14} \mathrm{C}$ offsets, which were found to be linked with maintenance periods conducted on these nuclear reactors.
\end{abstract}

\section{INTRODUCTION}

Over the past 2 decades, the global total emissions of $\mathrm{CO}_{2}$ from fossil fuel burning have increased from 6.45 PgC in 1990 to $8.75 \mathrm{PgC}$ in 2008 as reported by the Carbon Dioxide Information Analysis Center (CDIAC; http://cdiac.ornl.gov/trends/emis/annex.html). This global emission incre ase of $36 \%$ is rather sobering given the considerable efforts made by signatory nations within the Kyoto protocol to rather reduce fossil fuel $\mathrm{CO}_{2}$ emissions. In fact, the statistical data indicate that there are stark differences of the emission trends in different countries and regions. While Annex B countries (i.e. most of Europe, North America, and other industrialized countries) have reported almost constant emissions of 3.90 to $3.88 \mathrm{PgC} / \mathrm{yr}$, emissions from the Non-Annex B countries (i.e. China, India, and developing countries) have more than doubled from $2.11 \mathrm{PgC}$ in 1990 to $4.60 \mathrm{PgC}$ in 2008 , as reported by CDIAC. It is apparent that investigation of emissions and their trends requires regional-scale evaluation. The scientific community has begun moving towards independent validation of the published emission statistics using atmospheric observations (Levin and Rödenbeck 2008; Weiss and Nisbet 2010). This effort will be even more important as the statistical data from the Non-Annex B countries is subject to larger uncertainties than that in industrialized countries (Marland et al. 2009; Guan et al. 2012). To quantify the emissions of fossil fuel $\mathrm{CO}_{2}$ on a local and regional scale, measuring the depletion of the ${ }^{14} \mathrm{C} / \mathrm{C}$ ratio in ambient $\mathrm{CO}_{2}$ due to the local surplus of fossil fuel $\mathrm{CO}_{2}\left(\mathrm{CFFCO}_{2}\right)$, which is void of any ${ }^{14} \mathrm{C}$, is now a widely used technique (e.g. Levin et al. 2003; Turnbull et al. 2009b; Miller et al. 2012). Besides the influence from fossil fuels, tropospheric $\square^{14} \mathrm{C}$ levels are also altered by processes such as air-sea gas-exchange (e.g. Wanninkhof 1992; Naegler et al. 2006; Sweeney et al. 2007), intrusion of stratospheric air that is enriched in ${ }^{14} \mathrm{CO}_{2}$ (e.g. Rasch et al. 1994; Holton et al. 1995; Hesshaimer and Levin 2000), and biospheric

${ }^{1}$ Environment Canada, Climate Research Division, 4905 Dufferin St., Toronto, Ontario M3H 5T4, Canada.

${ }^{2}$ Now at Laboratoire de Sciences du Climat et de l'Environnement, 91191 Gif-sur-Yvette, France. Corresponding author. Email: Felix.Vogel@ lsce.ipsl.fr.

${ }^{3}$ Institut für Umweltphysik, Ruprecht-Karls-Universität Heidelberg, Im Neuenheimer Feld 229, 69120 Heidelberg, Germany . 
fluxes (e.g. Trumbore 2000; Turnbull et al. 2006) as well as emissions from the nuclear energy industry (e.g. Levin et al. 1980; Turnbull et al. 2009b; Graven and Gruber 2011). The first 2 components can be neglected in our approach of interpreting local gradients (cf. Section 2.2), while the latter two, namely, fluxes from the biosphere and emissions from the nuclear industry, must be taken into account.

Recently, the contribution from nuclear power plants has been identified as a potential source for large-scale gradients in $\square^{14} \mathrm{C}$ (Graven and Gruber 2011). This could affect our ability to correctly estimate fossil fuel $\mathrm{CO}_{2}$ levels from ${ }^{14} \mathrm{CO}_{2}$ measurements and must be addressed accordingly. In particular, as there is an obvious spatial correlation of the location of nuclear power plants and regions with high population density. This is especially true in cases when fuel reprocessing plants and nuclear power plants are located within relatively close proximity. The relatively large emissions of ${ }^{14} \mathrm{CO}_{2}$ would definitely be noticeable here (Levin et al. 1980). One type of reactor known to emit significant amounts of ${ }^{14} \mathrm{CO}_{2}$ is the Canadian Deuterium Uranium (CANDU) reactor (Robertson 1978). Globally, there are 48 CANDU reactors (or derivatives) currently in use or in the planning stage for operation. These reactors are primarily located in Canada, South Korea, India, and China. Although the present study focuses on the regional scale, it is an important case study to assess the only currently available global emission numbers from the nuclear industry of Graven and Gruber (2011) in a region that is expected to be a hot spot of anthropogenic ${ }^{14} \mathrm{CO}_{2}$ emissions. Furthermore, the fossil fuel $\mathrm{CO}_{2}$ observations conducted by Environment Canada here capture the most densely populated area of Canada.

In the following, we investigate first the differences between the parameterized inventory from Graven and Gruber (2011) and measured emissions compiled from the official emission reports of the Canadian Nuclear Safety Committee (CNSC). We also utilize a high-resolution modeling framework to investigate the influence of the different ${ }^{14} \mathrm{CO}_{2}$ emissions on the atmospheric ${ }^{14} \mathrm{CO}_{2}$ levels in comparison to the modeled ${ }^{14} \mathrm{C} / \mathrm{C}$ ratio depletion due to $\mathrm{FFCO}_{2}$ emissions on a regional scale. From this work, we then infer the possible bias of retrieved regional $\mathrm{FFCO}_{2}$ concentrations offsets at our observational site. Lastly, we use a 2-yr-long record of biweekly integrated air samples to assess the ${ }^{14} \mathrm{CO}_{2}$ emissions and postulate reasons for variations observed in the ${ }^{14} \mathrm{CO}_{2}$ on intraannual timescales.

\section{METHODS}

\subsection{Observations}

Figure 1 shows the location of Environment Canada's Centre for Atmospheric Research (CARE) in Egbert, Canada $\left(44.23^{\circ} \mathrm{N}, 79.78^{\circ} \mathrm{W}\right)$, where the air sampling for our ${ }^{14} \mathrm{CO}_{2}$ measurements was conducted. It is located $\sim 80 \mathrm{~km}$ northwest of the heavily populated Greater Toronto Area (GTA). This is a favorable distance for a network aimed at quantifying local/urban emissions. It is far enough away to observe an integrated signal from this area source and yet not too far to be concerned with too much diluted or altered signals. The GTA is inhabited by over 5.6 million people (StatsCan 2008), a key share of the 8.8 million inhabitants of the densely populated western shore of Lake Ontario, often referred to as the Golden Horseshoe area. In this study, we utilize 50 biweekly integrated $\mathrm{CO}_{2}$ samples collected from June 2008 to June 2010. The air drawn from a 25 -m-high tower is constantly purged through a Raschig-tube sampler filled with $250 \mathrm{~mL}$ of sodium hydroxide solution (Levin et al. 1980) at a flow rate of $\sim 75 \mathrm{~L} / \mathrm{hr}$. The $\mathrm{CO}_{2}$ within the air is absorbed in the caustic solution as it passes through the tube sampler. Approximately $25 \mathrm{~m}^{3}$ of air is passed through the sampler during the 14day sampling period. The $\mathrm{CO}_{2}$ samples are later analyzed with a precision of 2-3\% using the lowlevel counting technique at the University of Heidelberg, Germany (Kromer and Münnich 1992). 


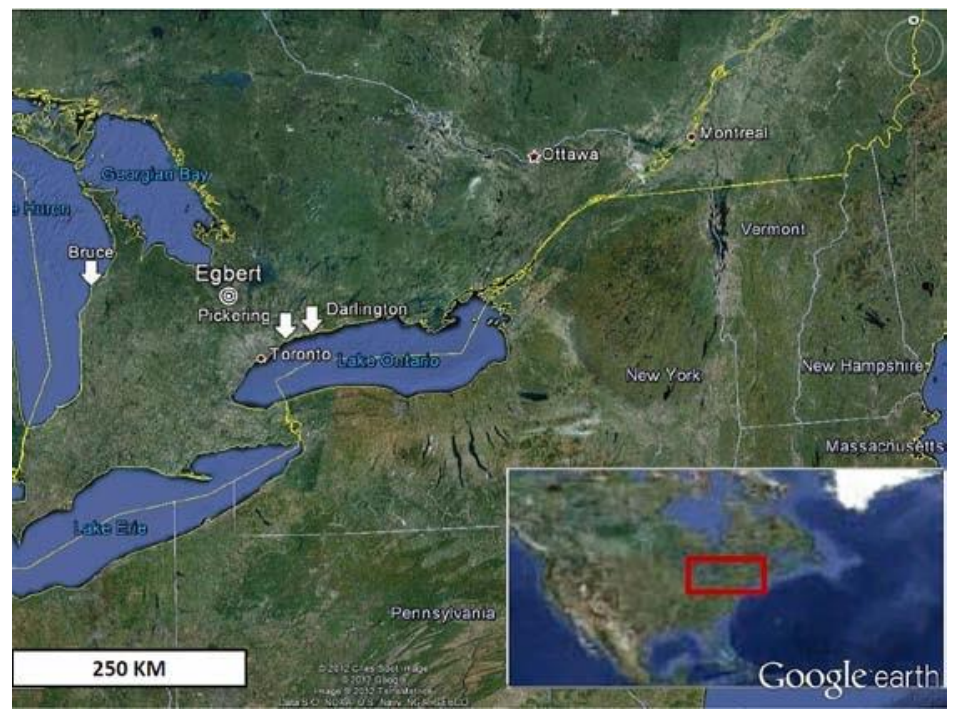

Figure 1 Map of the measurement site Egbert, Canada and the 3 nuclear generating stations Bruce, Pickering, and Darlington in the province of Ontario, Canada. This map was created using Google Earth ${ }^{\odot}$ (http://earth.google.com).

\subsection{Calculating Fossil Fuel $\mathrm{CO}_{2}$ from $\square^{14} \mathrm{C}$ Observations}

In order to interpret our measured $\square^{14} \mathrm{C}\left(\mathrm{Q}^{14} \mathrm{C}_{\text {meas }}\right.$; for the definition of the Delta scale, see Stuiver and Polach 1977) data correctly, we need to include all relevant processes influencing local $\square^{14} \mathrm{C}$. A thorough analysis of all contributions to the tropospheric $\square^{14} \mathrm{C}$ variations is given e.g. by Levin et al. (2010). Our focus here is the interpretation of alterations due to anthropogenic influences on $\square^{14} \mathrm{C}_{\text {meas }}$, which cause the isotopic composition to differ from background air $\square^{14} \mathrm{C}_{\mathrm{bg}}$, measured in the free troposphere (here, Jungfraujoch, Switzerland). Our measurements are used to assess the difference of the $\square^{14} \mathrm{C}_{\text {meas }}$ from ${ }^{14}{ }^{14} \mathrm{bg}$ and therewith infer the local excess of $\mathrm{CO}_{2}$ from the burning of fossil fuels. As $\mathrm{CFFCO}_{2}$ is void of ${ }^{14} \mathrm{C}$, its addition causes depletion in $\square^{14} \mathrm{C}\left(\mathrm{\square}^{14} \mathrm{C}_{\mathrm{FFCO}}\right)$. This approximation is, however, only valid for small $\mathrm{FFCO}_{2}$ offsets. From the mass conservation of $\mathrm{CO}_{2}$ and ${ }^{14} \mathrm{CO}_{2}$, one can derive that (Levin et al. 2003):

\section{$\mathrm{CO}$}

$$
\begin{aligned}
& { }^{F F C O}{ }_{2}=-\left(-a_{m e a s}{ }_{14} \mathrm{QD}_{14} C_{b g}\right. \\
& -\mathrm{C}_{14} C_{\text {meas }} \mathrm{\square} \\
& \text { ㄷ } C b g+1000 \%
\end{aligned}
$$

The relationship between the $\square^{14} \mathrm{C}_{\mathrm{FFCO} 2}$ (i.e. $\square^{14} \mathrm{C}_{\text {meas }} \square \square^{14} \mathrm{C}_{\mathrm{bg}}$ ) and $\square \mathrm{FFCO}_{2}$ is thus given by

$$
\mathrm{\square FFCO} \mathrm{O}_{2}=
$$$$
{ }_{14} C O C_{b g} 2 \square+1000 \text { meas }
$$$$
\% \circ \square{ }_{14}{ }_{F F C O 2}
$$ 
At first order, $\mathrm{ZFFCO}_{2}$ could be approximated by using a simple conversion factor and proposed slopes range from $\square 2.7$ to $\square 2.8 \% \mathrm{ppm}^{\square}$, in the literature for present-day levels of atmospheric $\mathrm{CO}_{2}$ in the background air (Turnbull et al. 2009a; Graven and Gruber 2011; Miller et al. 2012). Using a constant factor of $\square 2.8 \% \mathrm{ppm}^{\square_{1}}$ will, however, cause a bias of $\sim 1 \mathrm{ppm}$ for $15 \mathrm{ppm}$ of $\mathrm{GFCO}_{2}$. It is therefore not applicable for urban measurements, but a good approximation to estimate the firstorder effect of $\mathrm{CFFCO}_{2}$ on $\square^{14} \mathrm{C}$.

Although the local depletion of ${ }^{14} \mathrm{C}$ is often dominated by the local fossil fuel $\mathrm{CO}_{2}$ excess (cf. Figure 2), one must account for the influence of other ${ }^{14} \mathrm{CO}_{2}$ and $\mathrm{CO}_{2}$ sources on the $\square^{14} \mathrm{C}_{\text {meas }}$ if the measurements are intended to retrieve quantitative estimates of $\mathrm{aFFCO}_{2}$. Previous work has shown that the contribution from respiratory fluxes can have an effect on the ${ }^{14} \mathrm{CO}_{2}$ levels on both weekly (Turnbull et al. 2009b) and diurnal timescales (Vogel et al. 2010). Other studies estimated this respiratory flux to cause a $\square^{14} \mathrm{C}$ enhancement of $0.6 \%$ to $2 \%$ over North America (e.g. Turnbull et al. 2006; Hsueh et al. 2007). The translation of the observed $\square^{14} \mathrm{C}$ to $\triangle \mathrm{FFCO}_{2}$ must be expanded to account for these fluxes. We follow Levin and Rödenbeck (2008) to derive:

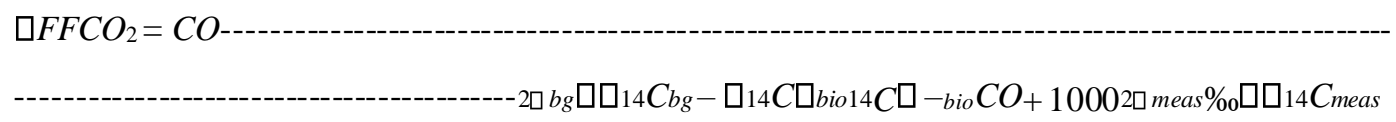

$-\square 14$ Cbio $\square$

For this study, we use extrapolated GRACE model results (Naegler and Levin 2009) to determine $\square^{14} \mathrm{C}_{\text {bio. }}$. The best estimate for 2010 is $96 \%$ for the heterotrophic respiration and we allow a large range of $76 \%$ to $116 \%$ for the uncertainty estimate. Our $\square^{14} \mathrm{C}_{\text {bio }}$ is in agreement with recent estimates for the enrichment of the heterotrophic respiration of $+40 \% 0$ compared to the atmospheric background $\square^{14} \mathrm{C}_{\mathrm{bg}}$ (Trumbore 2006). The autotrophic and aboveground respiration can be assumed to be in equilibrium with the atmospheric $\square^{14} \mathrm{C}$ (e.g. Trumbore 2006). A typical contribution of 6 ppm of $\mathrm{CO}_{2 \text {,bio }}$ thus results in a correction of $\square 0.3 \pm 0.1 \mathrm{ppm}$ (i.e. $0.9 \pm 0.3 \%$ ). For $\mathrm{CO}_{2 \text {,bio }}=19.6$ ppm (maximum), we retrieve a correction of $01.1 \pm 0.4$ ppm (i.e. $3.0 \pm 1.0 \%$ ).

Unfortunately, Equation 3 does not yet fully suffice as it neglects influences from the nuclear industry. The effect of ${ }^{14} \mathrm{CO}_{2}$ emissions from the nuclear industry has been previously assessed on local (Levin et al. 1980, 2003; Dias et al. 2008) and regional scales (Turnbull et al. 2009b). These studies were, however, limited to either very localized influences (for a single site) or they applied a constant correction and thus neglected larger-scale gradients. To monitor $\mathrm{FFCO}_{2}$ emissions on national and regional scales, the spatial distribution of sources must be taken into account. A global inventory for ${ }^{14} \mathrm{CO}_{2}$ emissions from the nuclear industry has been recently provided and its effect on large-scale $\square^{14} \mathrm{C}$ gradients has been investigated (Graven and Gruber 2011). This inventory gives a parameterization-based ${ }^{14} \mathrm{CO}_{2}$ emissions inventory (cf. Section 2.3). Graven and Gruber (2011) show that for some locations this nuclear component can be of the same order of magnitude as the depletion by fossil fuel $\mathrm{CO}_{2}$ emissions. Our site Egbert is located in one of the expected hot spots of anthropogenic ${ }^{14} \mathrm{CO}_{2}$.

To include the emissions of the nuclear industry, Equation 3 has to be expanded by a correction term. The complete equation was derived from the mass-balance of ${ }^{14} \mathrm{CO}_{2}$ and $\mathrm{CO}_{2}$. Note that we use $\square^{14} \mathrm{C}$ here, rather than $\mathrm{Q}^{14} \mathrm{C}$ (for the derivation see the Supplementary online material): 


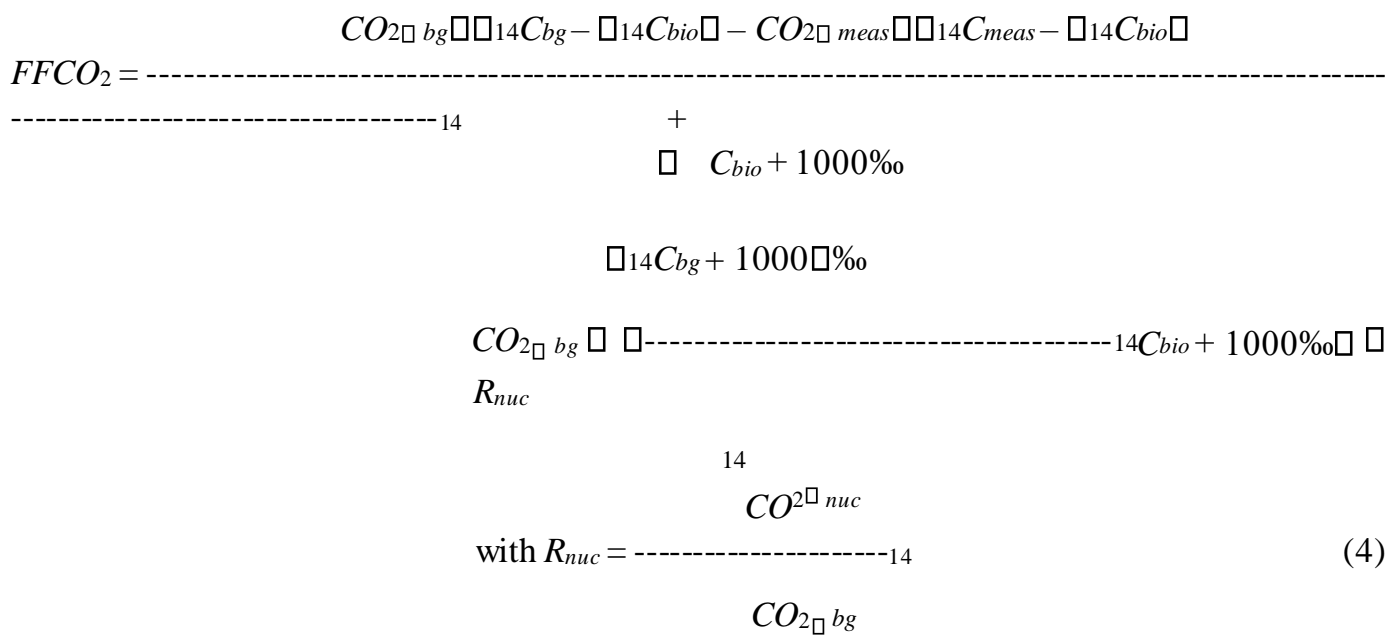

This formulation is an extension of Levin and Rödenbeck (2008). We can also choose to separate the fossil fuel depletion from the other (enriching) effects (see Supplementary online file).

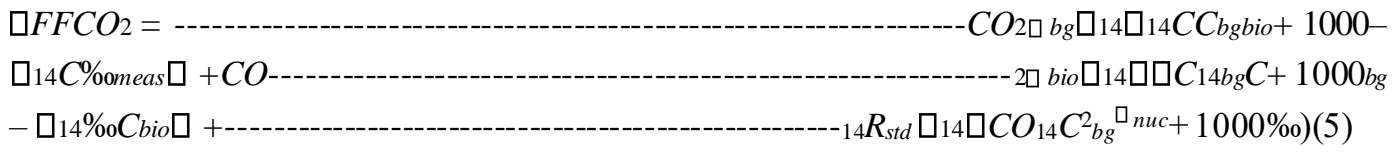

The first term on the right-hand side of Equation 5 reflects the observable $\square^{14} \mathrm{C}$ depletion, from which an apparent $\mathrm{DFFCO}_{2}\left(\mathrm{DFFCO}_{2 \text {,app }}\right)$ would be derived (cf. Figure 2). The second term of the right-hand side accounts for the biospheric influence and the third term accounts for the ${ }^{14} \mathrm{CO}_{2}$ emissions from the nuclear industry, which both mask the depletion in the atmospheric $\square^{14} \mathrm{C}$ level.

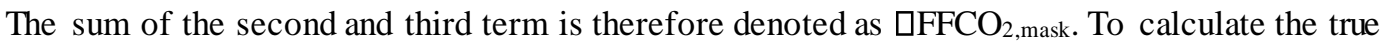
$\mathrm{DFFCO}_{2}$, one has to determine both $\mathrm{DFFCO}_{2, \text { app }}$ and $\mathrm{DFFCO}_{2 \text {,mask: }}$ :

$$
\square F F C O_{2}=\square F F C O_{2} a \text { app }+\square F F C O_{2} \square \text { mask }
$$

It is apparent that any uncertainty of $\triangle \mathrm{FFCO}$,mask will directly translate to an uncertainty of $\mathrm{DFFCO}_{2}$. In this study, we therefore investigate both the effect of the ${ }^{14} \mathrm{CO}_{2}$ emissions on our observed ${ }^{14} \mathrm{CO}_{2}$ as well as how the choice of an ${ }^{14} \mathrm{CO}_{2}$ emission data set can alter the modeled $\mathrm{DFFCO}$,mask. 


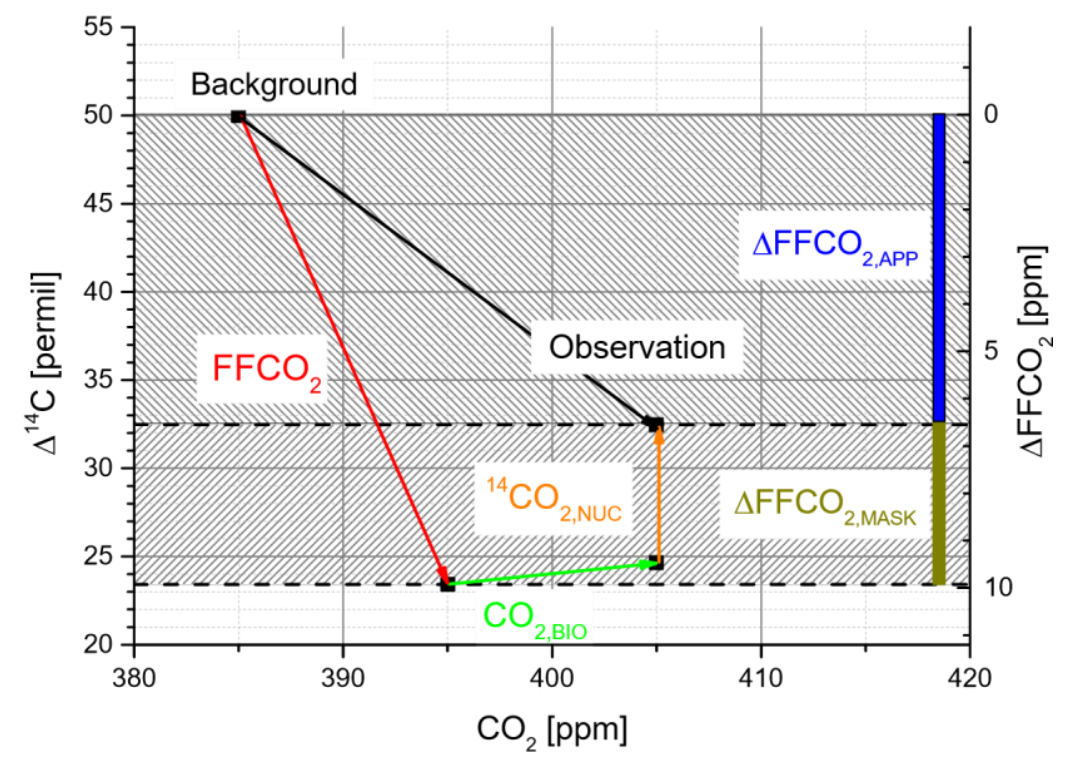

Figure 2 Schematic for the contributions to local variations of the $\square^{14} \mathrm{C}$ and $\mathrm{CO}_{2}$ levels for an exemplary situation with strong influence of fossil fuel $\mathrm{CO}_{2}$ and nuclear power plant ${ }^{14} \mathrm{CO}_{2}$ emissions $\left(\square \mathrm{FFCO}_{2}\right.$ and $\mathrm{CO}_{2 \text {,bio }}=10 \mathrm{ppm}, \square^{14} \mathrm{C}_{\mathrm{nuc}}=8 \%$ ). The observed values can be decomposed into measurement signal changes due to fossilfuel burning (red), biogenic fluxes (green), and emissions from the nuclear industry (orange). The $\square^{14} \mathrm{C}$ variations can be translated to $\mathrm{FFCO}_{2}$ with an apparent (blue) and a masked component (dark yellow).

\subsection{Inventory of ${ }^{14} \mathrm{CO}_{2}$ Emission from Nuclear Industry}

In this study, we use 2 different ${ }^{14} \mathrm{CO}_{2}$ emission inventory data sets from the nuclear industry. The basis for the comparisons is the recently publishedemissioninventory of Graven and Gruber (2011).

It is the first global inventory and has already been used in several studies (e.g. Andres et al. 2012; Graven et al. 2012; Miller et al. 2012). The ${ }^{14} \mathrm{CO}_{2}$ emissions therein are derived from published nuclear power plant electrical production data along with an assumed emission ratio of ${ }^{14} \mathrm{CO}_{2}$ per GWa electrical energy output. This parameterization-based estimate accounts for different types of reactors with emission factors ranging from $0.06 \mathrm{TBq}(\mathrm{GWa})^{\square_{1}}$ for pressurized-water reactors to 5.5 $\mathrm{TBq}(\mathrm{GWa})^{\square_{1}}$ for Magnox gas-cooled reactors. The emissions are reported to have large uncertainties, but this information is not explicitly included in the inventory. This is also the case for CANDU reactors, which have an average emission ratio of $1.6 \mathrm{TBq}(\mathrm{GWa})^{\square_{1}}$. Although not explicitly included in their publicly available inventory, Graven and Gruber (2011) report high uncertainties of these emission ratios of $300 \%$ up to $1000 \%$. The emissions of ${ }^{14} \mathrm{CO}_{2}$ from medical applications of isotopes and others are not included in the inventory, but are not expected to be relevant for our investigated domain. Their emissions are assumed to be 1-2 orders of magnitude lower than the emissions from CANDU reactors (Graven and Gruber 2011) and the largest medical isotope producing facility in Canada (Chalk River laboratories) is more than $350 \mathrm{~km}$ away from our site. For our domain, i.e. southern Ontario, influences on the atmospheric ${ }^{14} \mathrm{CO}_{2}$ levels are expected mostly from depletion due to fossil fuel $\mathrm{CO}_{2}$ and ${ }^{14} \mathrm{CO}_{2}$ emissions from the $3 \mathrm{CANDU}$ reactors. A 
detailed description of the processes involved in the production of ${ }^{14} \mathrm{CO}_{2}$ in this reactor type can be found in Beninson and Gonzalez (1982).

To investigate the interannual variability and emission behavior of the CANDU plants, we compiled the officially reported emissions from the Canadian Nuclear Safety Committee (CNSC). Monitoring of nuclear emissions is a legal requirement under the reporting requirements for operating nuclear power plants S-99 (http://nuclearsafety.gc.ca/pubs_catalogue/uploads/S99en.pdf). Our data here were compiled from the official Radiological Environmental Monitoring Programs (REMP) of the different licensees. The largest Canadian nuclear power plants are all located in the province of Ontario. The nuclear generating stations (NGS) in Pickering and Darlington are operated by OntarioPower Generation (http://www.opg.com) while the Bruce plant is operated by BrucePower (http:// www.brucepower.com). Both companies report annual emissions to CNSC. The emissions are also reported in the companies' official quarterly reports.

Airborne radiological emissions monitoring at the nuclear generating stations is conducted on all stacks. The samples are collected using a passive sampler that absorbs $\mathrm{CO}_{2}$ into soda lime pellets, which are later extracted and measured using counting techniques. The quality assurance protocol includes traceable standards and samples are only defined as valid if the accompanying quality control standard is within 10-20\% of the true value (REMP 2012). We have incorporated this in our uncertainty estimate. The ${ }^{14} \mathrm{CO}_{2}$ release dissolved in the water is also reported, but this has a negligible influence on the atmospheric ${ }^{14} \mathrm{CO}_{2}$ budget. In addition to stackmonitoring, the emissions are further validated using a dense ${ }^{14} \mathrm{CO}_{2}$ air-sampling network of 6-11 relatively nearby located monitoring sites that surround each nuclear power plant. Data from these sites is, however, only available as annual averages. In addition, there is a provincial monitoring network of 6 similar sites.

\subsection{Atmospheric Transport Modeling}

In order to interpret the observational $\mathrm{CO}_{2}$ data and estimate the influence of the nuclear power plant ${ }^{14} \mathrm{CO}_{2}$ emissions on the atmospheric ${ }^{14} \mathrm{C}$ levels at Egbert, we utilize a high-resolution modeling framework. The local offset (to Northern Hemispheric background) in the atmospheric concentrations of $\mathrm{CO}_{2}$ and ${ }^{14} \mathrm{CO}_{2}$ are derived using the Stochastic Time-Inverted Lagrangian Transport (STILT) model (Lin et al. 2003). STILT is based on the HySPLIT (Hybrid Single Particle Lagrangian Transport) model and is driven by meteorological data from the Eta Data Assimilation System (EDAS) of the National Atmospheric and Oceanic Administration (http:// ready.arl.noaa.gov/archives.php) with a spatial resolution of $40 \mathrm{~km}$ and 26 vertical levels. The STILT model is used to calculate the influence function $I\left(x_{r} t_{r} \square x, t\right)$ that links the sources and sinks $\mathrm{S}(\mathrm{x}, \mathrm{t})$ to the measured local concentrations offset $(\mathrm{\square C})$ compared to the background. The term $I\left(x_{r} t \quad \square x, t\right)$ represents the atmospheric mixing and determines the accumulation of tracers in the air parcels along its path to the measurement site at $x_{\mathrm{r}}$ and time $t_{r}$. Mathematically, this can be expressed as (cf. Lin et al. 2003; Gerbig et al. 2003):

$$
\square C x \square{ }_{r} t_{r} \square={ }_{x_{\text {oto }} d x d t I x \square{ }_{r} t_{r} \mid x t \square \square \square S x t \square \square \square}^{x_{r} t_{r}}
$$

We use this framework to simulate the added $\mathrm{CO}_{2}$ from fossil fuel burning and the added ${ }^{14} \mathrm{CO}_{2}$ released by the nuclear industry (e.g. power plants) in North America. Our modeling domain encompasses all (direct) influences from North America $\left(120^{\circ} \mathrm{W}\right.$ to $60^{\circ} \mathrm{W}$ and $30^{\circ} \mathrm{N}$ to $\left.60^{\circ} \mathrm{N}\right)$. 
Hourly footprints were generated from 300 particles released at $x_{r}$ with a back-trajectory time of 5 days. Trajectories are computed with variable time-step size fulfilling the Courant-FriedrichLewy condition, for which the resolution of the emission data (i.e. $10 \times 10 \mathrm{~km}$ ) was the basis. The typical time-step for which the particle displacement is calculated is $15 \mathrm{~min}$ and footprints are then computed with hourly time resolution. In order to derive $\mathrm{CO}_{2}$ concentrations, seasonally and longterm trends in the hemispheric background, the $\mathrm{CO}_{2}$ and $\mathrm{Q}^{14} \mathrm{CO}_{2}$ must be taken into account. We have used a smoothed fit of the observations for the Jungfraujoch $(\mathrm{JFJ})\left(46.55^{\circ} \mathrm{N}, 7.99^{\circ} \mathrm{E}, 3450\right.$ $\mathrm{m}$ asl) research station for our background signal. Previous studies have found that the difference of using JFJ observation compared to e.g. Alert, Canada $\left(82.50^{\circ} \mathrm{N}, 62.33^{\circ} \mathrm{W}\right)$ (Levin et al. 2010) as background is on the order of $2 \%$. The $\mathrm{JFJ}{ }^{14} \mathrm{CO}_{2}$ data clearly displays a seasonal cycle and the ongoing depletion in global $\square{ }^{14} \mathrm{C}$ levels (cf. Figure 7). The depletion of $\square^{14} \mathrm{C}$ due to the addition of fossil fuel $\mathrm{CO}_{2}$ at Egbert is calculated in a forward simulation using the anthropogenic emissions from EDGAR V4.1 with a resolution of $0.1^{\circ} \times 0.1^{\circ}$, i.e. approximately $11 \times 7 \mathrm{~km}$ (EDGAR 2011). We include a seasonal cycle correction of the $\mathrm{FFCO}_{2}$ emissions of approximately $15 \%$ based on the work by Nassar et al. (2012).

\section{RESULTS AND DISCUSSION}

\subsection{Inventory Comparison}

As a first step, it is crucial to compare the parameterized ${ }^{14} \mathrm{CO}_{2}$ emission from Gruber and Graven (2011) with the measured and officially reported emissions from the Canadian Nuclear Safety Committee (cf. Section 2.3). Graven and Gruber (2011) already reported large uncertainty for the powerbased emission factors for 2 CANDU facilities and speculated that better knowledge of the emission of individual sites could be required. Our study, which uses the data of all Canadian CANDU reactors, finds that the general tendency of increasing ${ }^{14} \mathrm{CO}_{2}$ emissions with increasing power output is clearly visible (cf. Figure 3 ). There is, however, a large variability for 2 of the major power plants in Ontario. For our annual emission data from 2000 to 2010, we find a mean emission factor for all CANDU reactors of $1.50 \pm 0.18 \mathrm{TBq}(\mathrm{GWa})^{{ }_{1}}$, which compares well with the official UNSCEAR estimate of $1.6 \mathrm{TBq}(\mathrm{GWa})^{\mathrm{D}_{1}}$ (UNSCEAR 1988, 1993, 2000). The interquartile range of $1.07 \mathrm{TBq}(\mathrm{GWa})^{\square_{1}}$ and the rather low $\mathrm{R}^{2}$ of 0.59 , however, suggests that a power output-based parameterization might be too simple. For the assessment of our observations at Egbert, the emissions from the facilities in the vicinity of our site Egbert are most important. The 3 relevant nuclear generating stations (NGS) are Pickering NGS $80 \mathrm{~km}$ to the southeast, Darlington NGS 100 $\mathrm{km}$ to the southeast, and Bruce NGS $150 \mathrm{~km}$ to the west (cf. Figure 1). 


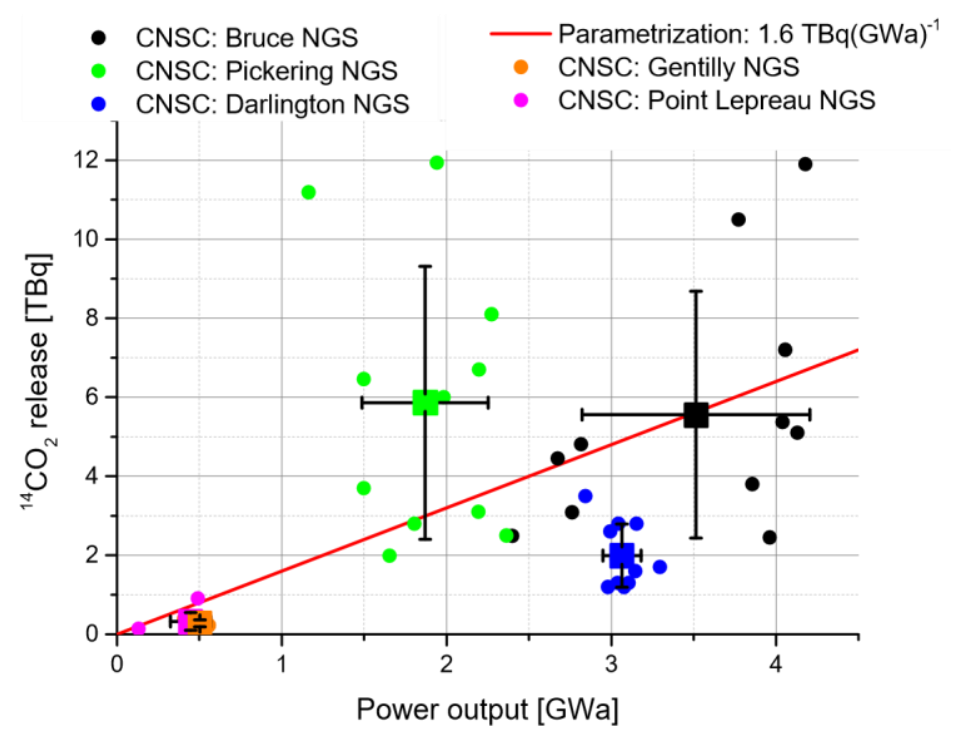

Figure 3 Comparison of predicted emissions from power output-based parameterization (red line) with emission data from 2000 to 2010 reported by CNSC for Bruce NGS (black), Darlington NGS (blue), Pickering NGS (green), Gentilly NGS (orange), and Point Lepreau NGS (magenta).

The average ratio for Bruce NGS of $1.55 \pm 0.22 \mathrm{TBq}(\mathrm{GWa})^{\square_{1}}$ compares well with the parameterization value of $1.6 \mathrm{TBq}(\mathrm{GWa})^{\square_{1}}$, whereas the emission ratio of Pickering NGS of $3.4 \pm$ $0.82 \mathrm{TBq}(\mathrm{GWa})^{\square_{1}}$ lies significantly above this (see also: UNSCEAR 1988, 1993, 2000). On the other hand, the Darlington NGS emission ratio of $0.65 \pm 0.09 \mathrm{TBq}(\mathrm{GWa})^{\square_{1}}$ is well below. In addition, particularly, for the 2 major emitters, Bruce NGS and Pickering NGS, we find high interannual variability of the emission ratio with interquartile ranges of 0.74 and $2.60 \mathrm{TBq}(\mathrm{GWa})^{\square_{1}}$, respectively. The parameterized emission inventory is not able to resolve these features because the power output of the respective power plants did not show similar variability. For the years not included in the original Graven and Gruber (2011) inventory, the ${ }^{14} \mathrm{CO}_{2}$ emissions are extrapolated according to the methodology described therein.

The variability in the emission ratio, omitted in the parameterized inventory, automatically translates into a deviating ${ }^{14} \mathrm{CO}_{2}$ emission estimate. This strong interannual variability of the emissions can cause significant trends in the total amount of ${ }^{14} \mathrm{CO}_{2}$ emitted in Ontario as seen in Figure 4. We find that interannual emissions of the parameterized estimate are fairly constant during the first decade of the 2000s, but we see strong excursions in the CNSC reported data. We are able to back track these variations to underlying processes. For example, a major driver for the increased total emissions was ${ }^{14} \mathrm{CO}_{2}$ released by the Pickering NGS from 2005 to 2008 . These emissions were caused by a calandria tube that leaked carbon dioxide from the annulus gas into the Unit 7 moderator system. The emission level has since returned to pre-2005 levels following the April 2008 replacement of the failed calandria tube (REMP 2012). The reduction of the ${ }^{14} \mathrm{CO}_{2}$ emissions of Bruce NGS since 2006 can be traced to an increased focus on moderator purification and resin management (REMP 2012). 


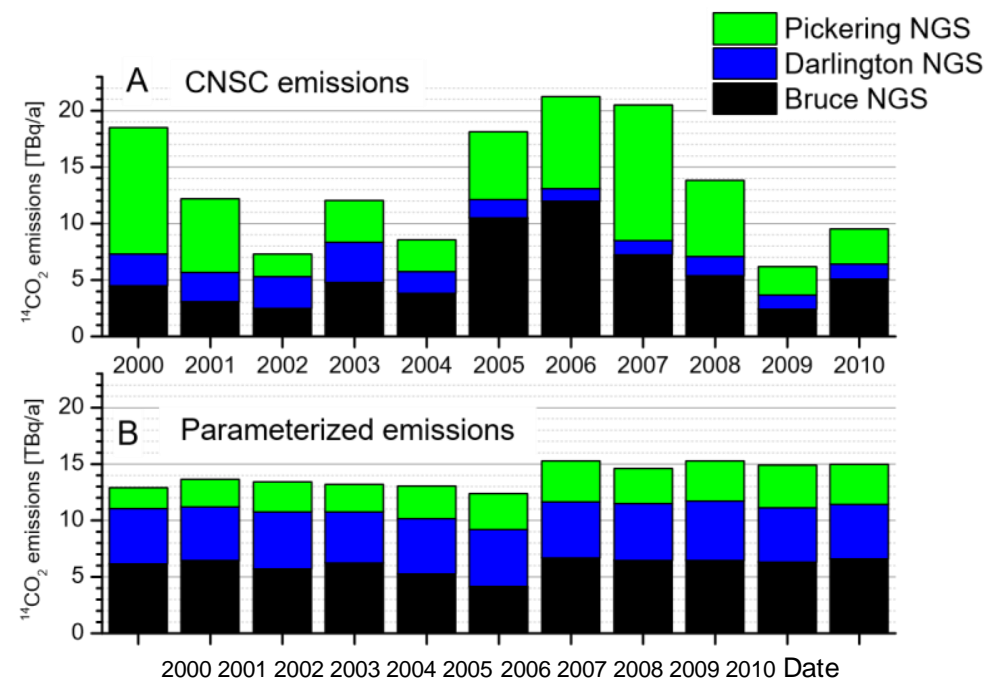

Figure 4 Comparis on of annual ${ }^{14} \mathrm{CO}_{2}$ emissions from nuclear power plants in Ontario, Canada, from the parameterized inventory and the emissions reported by CNSC.

\subsection{High-Resolution Modeling of the ${ }^{14} \mathrm{CO}_{2}$ Concentration Excess from Nuclear Power Plants}

After analyzing the emission data, we need to investigate the effect of the different bottom-up emissions on the modeled ${ }^{14} \mathrm{CO}_{2}$ concentrations. We ran 2 simulations using the STILT-EDAS model (cf. Section 2.4) for both the reported as well as the parameterized emissions (cf. Section 2.3) to infer the atmospheric ${ }^{14} \mathrm{CO}_{2}$ concentration excess at our Egbert site. In order to evaluate the importance of differing emissions from the CANDU reactors we first compare their emissions with the contributing emissions from all other (Non-CANDU) reactors in North America (Figure 5). Because the other sources, as shown in Figure 5, have such a negligible influence, we can safely assume that the variations in our simulations are almost exclusively driven by emissions from the CANDU reactors. The general temporal pattern and variability of the modeled ${ }^{14} \mathrm{CO}_{2}$ concentration time series (Figure 5) is quite similar for both emission scenarios. This is due to the fact that the signals are mainly driven by changing meteorological conditions. In our example period for 2008 , we find large ${ }^{14} \mathrm{CO}_{2}$ concentration excess during situations when Egbert is downwind of the CANDU nuclear power plants. This is generally followed by rapid decreases when the wind changes to other sectors. Although both simulations display similar temporal patterns, they are, however, easily distinguishable. The simulated ${ }^{14} \mathrm{CO}_{2}$ concentrations using the parameterized emissions $\left({ }^{14} \mathrm{CO}_{2 \text {,para }}\right)$ are on average $14 \%$ below those when using the reported emissions $\left({ }^{14} \mathrm{CO}_{2, \mathrm{CNSC}}\right)$. The ratio of

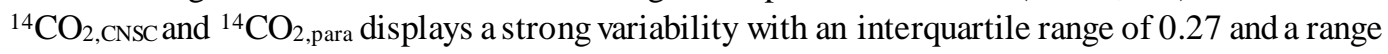
from 0.5 to 2.0 .

\subsection{Implications for $\mathrm{\square FFCO}{ }_{2}$ Estimates from Pseudo-Data Experiment}

To infer the impacts of our findings on potential monitoring of $\mathrm{CFFCO}_{2}$ using atmospheric ${ }^{14} \mathrm{CO}_{2}$ observations, we conducted a pseudo-data experiment. As discussed in Section 2.2, it is crucial to determine both the apparent $\mathrm{GFFO}_{2}(\mathrm{\square FFCO}$,app $)$ as well as the masked fraction $\left(\mathrm{QFFCO}_{2, \text { mask }}\right)$ to infer the true $\mathrm{DFFCO}_{2}$. Because $\mathrm{\square FFCO}$, mask must be determined using a modeling framework, we

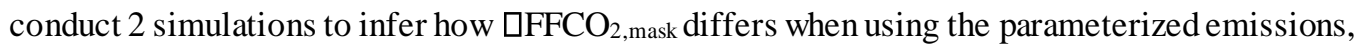




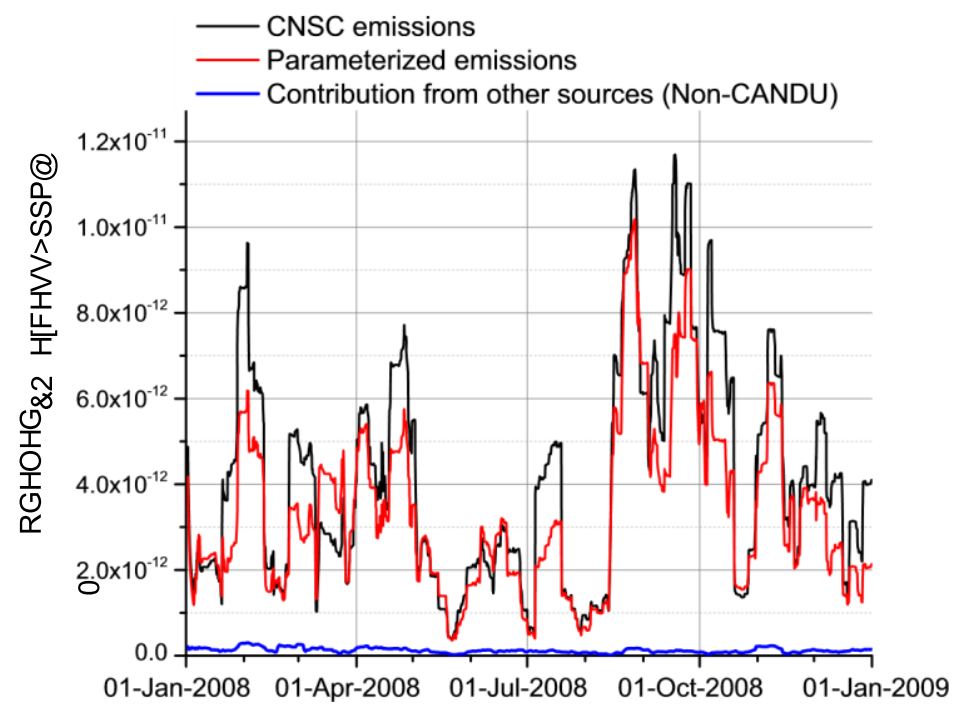

Figure 5 Modeled atmospheric excess of ${ }^{14} \mathrm{CO}_{2}$ due to emissions from CANDU reactors (parameterized emissions in red and reported emissions in black) and other anthropogenic ${ }^{14} \mathrm{CO}_{2}$ sources (blue) in Egbert, Canada.

rather than the reported emissions. At first, we simulate $\mathrm{BFFCO}_{2}$ using EGDAR V4.1 (EDGAR 2011) including seasonal variations of emissions. The annual total of the fossil fuel $\mathrm{CO}_{2}$ emissions from 2005 was used for all following years. The modeled $\mathrm{DFFCO}_{2}$ in Egbert based on EDGAR is on average $4.8 \pm 0.2 \mathrm{ppm}$ for the period from 2006 to 2011 . The small year-to-year variations can be explained by the changing meteorology (i.e. area of influence) for the different years. As a second step the masked fraction, i.e. $\mathrm{\square FFCO}$, mask is then calculated using the ${ }^{14} \mathrm{CO}_{2}$ emissions reported by CNSC (cf. Figure 6A). We find that $\mathrm{QFFCO}_{2}$, mask is on average $56 \%$ of $\mathrm{\triangle FFCO}_{2}$, but varies significantly from year to year from $27 \%$ in 2009 to $82 \%$ in 2007. By subtracting $\mathrm{DFFCO}_{2 \text {,mask }}$ from $\mathrm{DFFCO}_{2}$, we derive $\mathrm{GFFCO}_{2, \text { app }}$. For the purpose of this study, we now assume that our derived $\mathrm{CFFCO}_{2, \text { app }}$ is correct. A comparison between modeled $\mathrm{CFFCO}_{2}$ and observed $\mathrm{CFFCO}_{2}$, which displays the limits of this assumption, is given in Section 3.4.

To investigate the effect of the using a different ${ }^{14} \mathrm{CO}_{2}$ emission data set, i.e. parameterized ${ }^{14} \mathrm{CO}_{2}$ emission inventory according to Graven and Gruber (2011), we now have to perform another

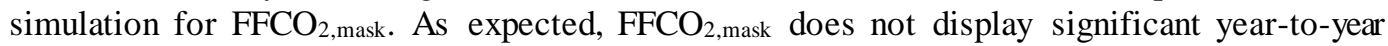
changes now (cf. Figure 6B). By adding $\mathrm{DFFCO}_{2}$,app, we can derive the new $\mathrm{DFFCO}_{2}$. We find an average $\mathrm{CFFCO}_{2}$ of $4.5 \pm 1.3 \mathrm{ppm}$ in the parametrization-based simulation, which is comparable to the previous value but has a 6 -fold larger standard deviation. Here, $\mathrm{DFFCO}_{2}$, mask accounts for $49 \%$ of $\mathrm{DFFCO}_{2}$ and has a narrow range of 41-55\%. A most important fact for possible interpretation of a $\mathrm{DFFCO}_{2}$ time series is how the concentrations develop over time. For 2006-2011, we find that a spurious trend of about $30 \%$ for $\mathrm{DFFCO}_{2}$ emerges. In a simple inversion scheme, this trend in the local offset could translate into an increase of the estimated emissions of the same order of the magnitude for this time period. 
Besides the problem of retrieving temporal trends of $\mathrm{DFFCO}_{2}$ correctly, one has to be aware that not properly accounting for $\mathrm{DFFCO}_{2}$,mask can as well cause a misinterpretation of spatial gradients. These in turn can then cause significant errors when deriving the spatial distribution of local fluxes from atmospheric observations.
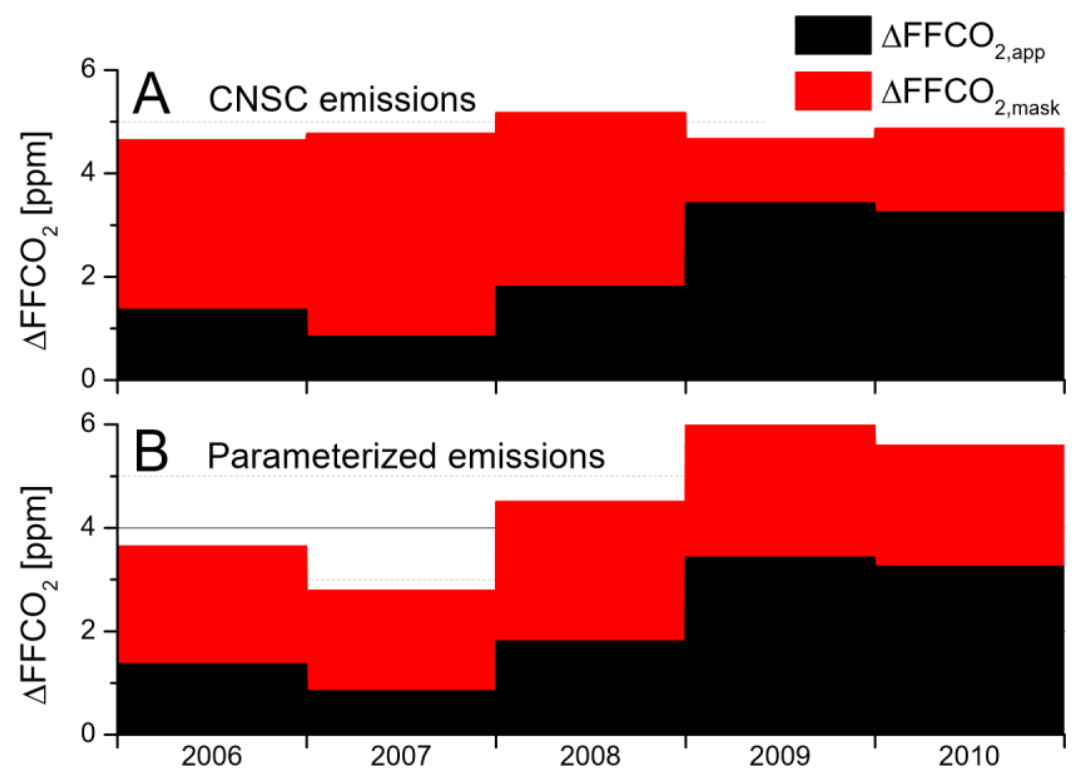

Figure 6 Modeled $\mathrm{FFCO}_{2}$ (and its components according to Equation 5) using EDGAR V4.1 fossil fuel $\mathrm{CO}_{2}$ emissions and (A) $\mathrm{CNSC}$ reported ${ }^{14} \mathrm{CO}_{2}$ emissions and (B) parameterized ${ }^{14} \mathrm{CO}_{2}$ emissions.

\subsection{Comparison of Model Results and Observational Data}

After determining the impact of reported vs. parameterized ${ }^{14} \mathrm{CO}_{2}$ emissions from the nuclear industry, we focus on the question whether the use of the CNSC reported emissions is sufficient to adequately correct the apparent $\mathrm{QFFCO} 2$ for the addition of ${ }^{14} \mathrm{CO}_{2}$ from these sources. Our 2-yr-long observational record of $\square^{14} \mathrm{CO}_{2}$ in Egbert (cf. Section 2.1) forms the basis for this assessment. In Figure $7 \mathrm{~A}$, the $\square^{14} \mathrm{C}_{\text {meas }}$ data from Egbert do not consistently show the expected depletion patterns when compared to the background value. There are several situations when the $\square^{14} \mathrm{C}_{\text {meas }}$ surpasses $\square^{14} \mathrm{Cbg}_{\mathrm{bg}}$. This emphasizes the strong influence that nuclear power plant emissions have on this record. The modeled $\square^{14} \mathrm{C}$ using the STILT/EDAS-EDGARV4.1 framework shown in Figure 7 is derived by adding the modeled depletion due to the fossil fuel $\mathrm{CO}_{2}$ emissions (cf. Section 2.4) and $\square^{14} \mathrm{C}_{\mathrm{bg}}$. We find that $\square^{14} \mathrm{C}_{\text {meas }}$ deviates very strongly from this $\square^{14} \mathrm{C}_{\text {mod. }}$. As expected, when corrected with $\mathrm{DFFCO}_{2 \text {,mask }}$ the agreement with $\mathrm{Q}^{14} \mathrm{C}_{\text {mod }}$ is significantly improved. In addition, the general level as well as the seasonal pattern is met and there is strong improvement in the winter of 2009/2010. This clearly demonstrates the need to apply a nuclear industry correction at the Egbert site. Although a previous study by Graven and Gruber (2011) did unfortunately not have a suitable modeling framework, they already suggested that better resolved ${ }^{14} \mathrm{CO}_{2}$ emission data could improve our

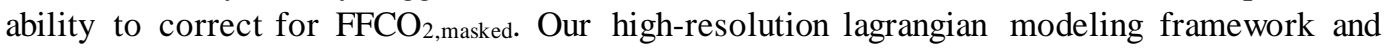


observations can now confirm this. The benefit of correcting the apparent $\mathrm{QFFCO}_{2}$ (derived from the observations alone) with the modeled $\mathrm{DFFCO}$, mask to retrieve the true $\mathrm{DFFCO}_{2}$ is illustrated in Figure 7B. While the mean of the uncorrected observations (i.e. the apparent $\mathrm{CFFCO}_{2}$ ) is $1.4 \mathrm{ppm}$ (standard error $0.3 \mathrm{ppm}$ ) for the period from June 2008 to June 2010, the corrected average is $4.2 \pm$ $0.6 \mathrm{ppm}$, which is close to the modeled $\mathrm{DFFCO}_{2}$ of $5.1 \mathrm{ppm}$ (standard error $0.3 \mathrm{ppm}$ ). The uncertainty estimate of $\pm 0.6 \mathrm{ppm}$ for the observed $\mathrm{DFFCO}$ includes a $20 \%$ uncertainty for the ${ }^{14} \mathrm{CO}_{2}$ correction and the standard error of the observations. Including the uncertainty of the biospheric ${ }^{14} \mathrm{CO}_{2}$ correction did not significantly increase this uncertainty. The influence of erroneous atmospheric transport modelling on both $\mathrm{DFFCO}_{2}$,mask as well as the modeled $\mathrm{FFCO}_{2}$ might be significant but is hard to quantify. For the modeled $\mathrm{DFFCO}_{2}$, the standard error (i.e. $0.3 \mathrm{ppm}$ ) should only be regarded as the lower bound of the uncertainty. Peylin et al. (2011), for example, reported an uncertainty due to model transport for an ensemble of atmospheric transport models for an urban site near Costana, Romania, of $0.6 \mathrm{ppm}$ for monthly averages. As our modeling framework is better resolved, we might expect this to be the upper bound of the transport model uncertainty. One could also expect that the transport model uncertainty is further decreased for long-term averages such as our 2-yr mean.

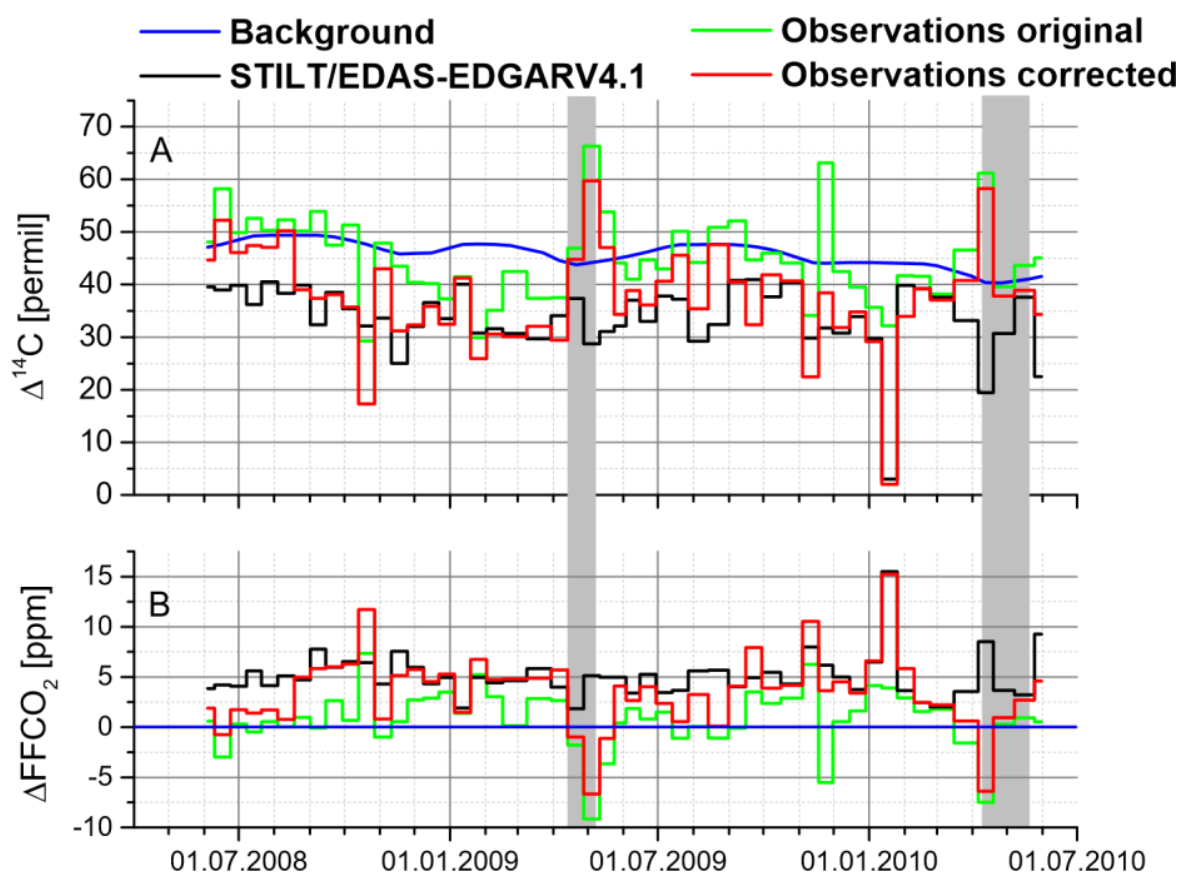

Figure $7 \mathrm{~A}$ ) The modeled $\mathrm{a}^{14} \mathrm{C}$ data (including $\mathrm{FFCO}_{2}$ emissions) in Egbert are given in black, the originally observed data in green, the corrected observations in red and compared to the $\square^{14} \mathrm{C}$ of the Northern Hemispheric background (i.e. Jungfraujoch). B.) $\mathrm{CFFCO}_{2}$ derived from the $\square^{14} \mathrm{C}$ data (same color code). Episodes of reported major maintenance at the nuclear power plants is given in gray (see text).

The observed and modeled $\mathrm{GFFCO}_{2}$ data display similar long-term variations as well as sampletosample variability. This data, however, is only included to illustrate the possible impact of failing to properly account for ${ }^{14} \mathrm{CO}_{2}$ emissions, while a detailed discussion of the comparison of modeled 
and observed $\mathrm{DFFCO}_{2}$ is beyond the scope of this paper. The uncertainties of the means given are the standard error, with the data for 2 episodes in spring 2009 and 2010 (gray areas in Figure 7) being neglected. We find that the correction is not sufficient during these 2 episodes. The enhancement implies the correction is too small, thus suggesting even larger ${ }^{14} \mathrm{CO}_{2}$ emissions from the nuclear power plants during these periods. From the REMP report, we have learned that during these periods, extensive maintenance and reconstructions were performed at the Darlington NGS (15 April-3 May 2009) and Pickering NGS (15 April-24 May 2010). When assuming that the difference of our observed and modeled data is caused by enhanced emissions during these episodes, we can retrieve an emission estimate using STILT/EDAS. We find that during the maintenance episodes, the ${ }^{14} \mathrm{CO}_{2}$ emissions are increased by a factor of 9 for the Darlington NGS and by a factor of 15 for the Pickering NGS, respectively.

The data from these 2 episodes are thus neglected in the quantitative assessment. Figure 8 shows that the raw observational $\square^{14} \mathrm{C}$ has only a weak correlation with the modeled $\square{ }^{14} \mathrm{C}$, with $\mathrm{R}=0.39$. The slope of $0.43 \pm 0.15$ and the large intercept of $30 \pm 5 \%$ suggest that uncorrected $\square^{14} \mathrm{C}_{\text {meas }}$ can basically not be used to retrieve a reasonable estimate of $\mathrm{QFFCO}_{2}$ at Egbert. The results when using the parameterized ${ }^{14} \mathrm{CO}_{2}$ emissions to correct $\square^{14} \mathrm{C}_{\text {meas }}$ is given for comparison, but only show minor improvements. When using the CNSC emissions as the basis for the corrected $\left[{ }^{14} \mathrm{C}_{\text {meas }}\right.$, the retrieved slope of 1.01 \pm 0.14 is in agreement with a 1:1 line and shows that the corrected observations of $\mathrm{Q}^{14} \mathrm{C}$ can be used to infer $\mathrm{CFFCO}_{2}$. The corrected data have an improved correlation of $\mathrm{R}=0.74$ with the model results. The remaining variability of the data set is most likely caused by intra-annual variability of the ${ }^{14} \mathrm{CO}_{2}$ emissions from the CANDU power plants and an erroneous representation of atmospheric transport in the used model. Errors in the spatial distribution of the fossil fuel $\mathrm{CO}_{2}$ emission inventory in the Greater Toronto Area, which are known to be significant for other anthropogenic greenhouse gases (Vogel et al.2012), may contribute as well. The small general offset of $2 \pm 5 \%$ is statistically in agreement with zero, but could point towards a small underestimation of the contribution from local biospheric ${ }^{14} \mathrm{CO}_{2}$ fluxes or, as mentioned above, be due to the choice of our background.

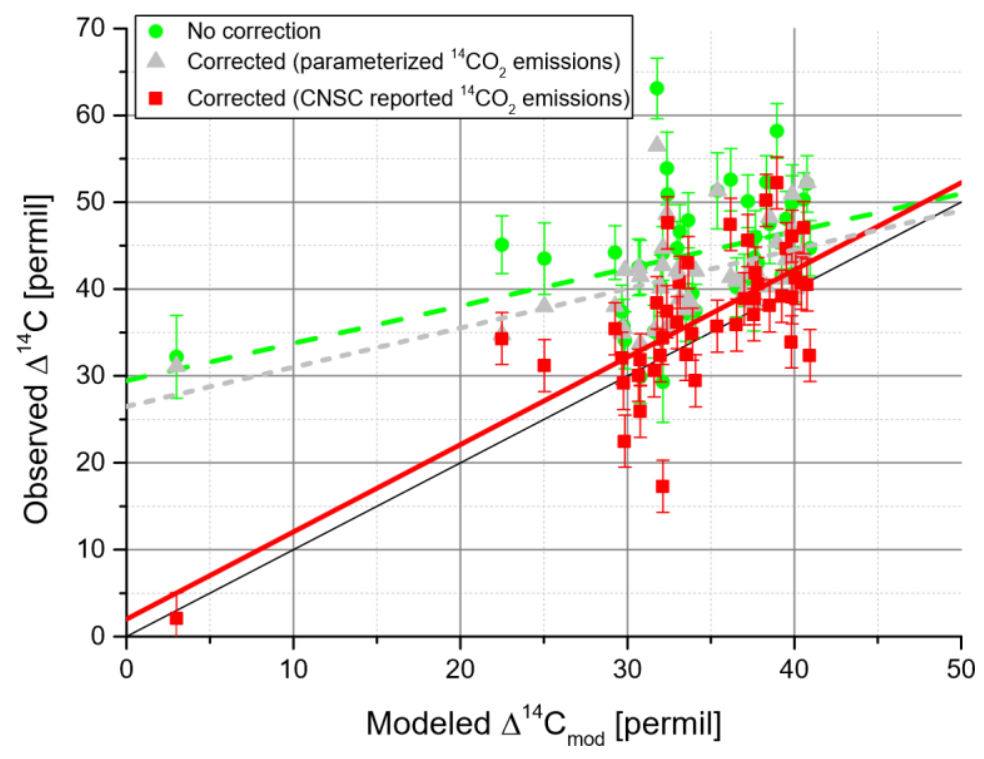


Figure 8 Comparing the STILT-EDAS modeled atmospheric $\square^{14} \mathrm{C}$ to the observed $\square^{14} \mathrm{C}$ (green circles) and $\square^{14} \mathrm{C}$ after applying the nuclear power plant correction using the parameterized emission model (gray triangles) and the CNSC emissions (red squares). The error bars denote the analytical precision for the observed $\square^{14} \mathrm{C}$ and an additional $20 \%$ uncertainty of the $\square^{14} \mathrm{C}$ correction for the CNSC-based correction. For clarity, no error bars are shown for the parameterized $\square^{14} \mathrm{C}$ corrections, but they can span up to $1000 \%$ (see section 2.3).

\section{SUMMARY AND CONCLUSION}

This study aimed at assessing the implications of nuclear power plant ${ }^{14} \mathrm{CO}_{2}$ emissions on deriving $\mathrm{DFFCO}_{2}$ estimates in a densely populated region that can be expected to be a hot spot of anthropogenic ${ }^{14} \mathrm{CO}_{2}$ emissions (Graven and Gruber 2011). For this task, we used 3 data sets: 1) 10 yr (2000-2011) of measured and officially reported ${ }^{14} \mathrm{CO}_{2}$ emissions from the Canadian Nuclear Safety Committee (CNSC) and a parameterized ${ }^{14} \mathrm{CO}_{2}$ emissioninventory; 2 ) the results of our highresolution modeling study (2006-2011); and 3) 2 yr (June 2008-June 2010) of observed atmospheric $\square^{14} \mathrm{C}$ at Egbert, Canada, as well as Northern Hemispheric background $\square^{14} \mathrm{C}$.

The first step of comparing the parameterized emissions to the reported emission data uncovered that the assigned emission ratio of $1.6 \mathrm{TBq}(\mathrm{GWa})^{\square_{1}}$ in the parameterization is in agreement with the measured average of all CANDU reactors of $1.50 \pm 0.18 \mathrm{TBq}(\mathrm{GWa})^{\square_{1}}$ as an overall mean. We could also quantify the emission ratio deviations using data from all Canadian CANDU reactors, which range from $0.65 \pm 0.09$ to $3.4 \pm 0.82 \mathrm{TBq}(\mathrm{GWa})^{\square_{1}}$. A parameterized inventory is, furthermore, not able to correctly describe the interannual variability of the (average) ${ }^{14} \mathrm{CO}_{2}$ emissions, which have an interquartile range of $1.07 \mathrm{TBq}(\mathrm{GWa})^{\square_{1}}$. Graven and Gruber (2011) reported large uncertainties and suggested that better resolved ${ }^{14} \mathrm{CO}_{2}$ emission data would be needed. Our study could show that using a parameterized approach is not suitable to derive ${ }^{14} \mathrm{CO}_{2}$ emissions in a hot spot region with multiple power plants and that regional studies should account for the different emission ratios of individual reactors. Ideally, the reactor-specific emission data should be compiled in future inventories and a parameterization-based approach be only used for regions that lack an official reporting.

To infer the influence of the different ${ }^{14} \mathrm{CO}_{2}$ bottom-up emissions on the atmospheric ${ }^{14} \mathrm{CO}_{2}$ levels, we conducted a pseudo-data experiment. From the modeled ${ }^{14} \mathrm{CO}_{2}$ time series (2006-2011), we learned that using different ${ }^{14} \mathrm{CO}_{2}$ emissions causes modeled ${ }^{14} \mathrm{CO}_{2}$ to deviate significantly and the

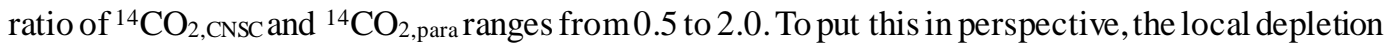
of $\mathrm{Q}^{14} \mathrm{C}$ due to the addition of fossil fuel $\mathrm{CO}_{2}$ was examined for our modeled time series from 2006 to 2011. We found that for the reported nuclear industry emissions, the annual average of the masked share accounts for $56 \%$ of $\mathrm{DFFCO}_{2}$ and ranges from $27 \%$ in 2009 to $82 \%$ in 2007 . This underlines the importance of a proper correction of the nuclear ${ }^{14} \mathrm{CO}_{2}$ emissions in this region as it sometimes outweighs the actual signal we are after (i.e. the $\square^{14} \mathrm{CO}_{2}$ depletion due to $\mathrm{FFCO}_{2}$ emissions) even though our site is on the fringe of the most densely populated area of Canada. The simulation using the parameterized emissions is able to nearly reproduce the average annual value of masked $\mathrm{CFFCO}_{2}$, yet the variability of $41-56 \%$ is severely underestimated. For our study period (20062011 ), this translates into a spurious trend of about $30 \%$ in the calculated $\mathrm{DFFCO}_{2}$. This might cause 
a misinterpretation of either the temporal variations of the $\mathrm{FFCO}_{2}$ emissions or the spatial distribution of the $\mathrm{FFCO}_{2}$ sources, if they were used in an atmospheric inversion framework.

We used our 2-yr-long observational time series from Egbert, Ontario, to assess if applying the CNSC reported ${ }^{14} \mathrm{CO}_{2}$ emissions is sufficient to adequately model the local ${ }^{14} \mathrm{CO}_{2}$ excess and thus

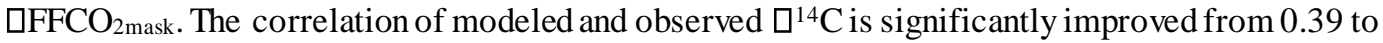
0.74. Even more importantly, the slope of $\square^{14} \mathrm{C}_{\mathrm{mod}}$ to $\square^{14} \mathrm{C}_{\mathrm{obs}}$ changes to $1.01 \pm 0.14$ from previously $0.43 \pm 0.15$, thus permitting us to reliably estimate $\mathrm{CFFCO}_{2}$ from the depletion in $\square^{14} \mathrm{C}_{\mathrm{obs}}$. The observed, apparent $\mathrm{DFFCO}_{2}$ for our time period of $1.4 \pm 0.4 \mathrm{ppm}$ is corrected to $4.2 \pm 0.6 \mathrm{ppm}$, which is close to the STILT/EDAS-EDGARV4.1 model result of $5.1 \pm 0.3 \mathrm{ppm}$ for this time series. One can expect that both biases and uncertainties in the $\mathrm{FFCO}_{2}$ fluxes as well as transport model biases and uncertainties contribute to the model-observation mismatch. Other studies have indicated that the greenhouse gas emissions of the Greater Toronto Area are overestimated in EDGARV4.1 (Vogel et al. 2012). The transport model error will affect both the modeled $\mathrm{CFFCO}_{2}$ as well as the calculation of $\mathrm{DFFCO}_{2}$,mask. Future studies aiming to quantify $\mathrm{FFCO}_{2}$ fluxes by interpreting the model-observation mismatch of individual samples rather than long-term averages will need to quantify the model transport error.

Although our applied ${ }^{14} \mathrm{CO}_{2}$ correction seems sufficient on average, we find significantly elevated $\square^{14} \mathrm{C}$ values in individual biweekly integrated samples. This points towards a neglected intra-annual variability. Combining the observations with our high-resolution modeling framework we find that the ${ }^{14} \mathrm{CO}_{2}$ fluxes of specific nuclear power plants can increase by a factor of 9 to 15 during maintenance periods. As maintenance work has to be performed on a regular basis, e.g. every $5 \mathrm{yr}$, any long-term monitoring program will have to account for this. This type of emissions can be assumed to be intermittent and the area of influence for our observations can also change rapidly. Therefore, ${ }^{14} \mathrm{CO}_{2}$ emission data on daily or synoptic timescale would be desirable. This seems unrealistic at the moment, but weekly to monthly average ${ }^{14} \mathrm{CO}_{2}$ emissions might be feasible for many sites and would decrease the uncertainty of $\mathrm{CFFCO}_{2 \text {,mask }}$ and help to identify situations where the observational data needs to be flagged. Until these high-resolution emission inventories are available, data flagging might be an option for sites within hot spot regions (like Egbert), as the signal is noticeable in the observed $\square^{14} \mathrm{C}$ time series. Identifying such periods at sites further downwind of the nuclear power plant site will, however, be challenging. Although the effect will be smaller there, it, if not accounted for, can still cause a (significant) bias in the fossil fuel $\mathrm{CO}_{2}$ estimate. This is especially noteworthy as the highly populated regions e.g. the NE coast of America can be affected by CANDU and other nuclear reactors. Previous studies estimated that the emissions of the nuclear industry account for a masking of about $0.2-0.8 \mathrm{ppm}_{\mathrm{DFFCO}}$ (monthly average) for a site downwind of Ontario (Miller et al. 2012) or ratios of $\mathrm{DFFCO}_{2 \text {, mask }}$ to $\mathrm{GFFCO}_{2}$ of $0-90 \%$ (Graven and Gruber 2011). Our study suggests that the influence of Canadian CANDU reactors should be expected to be at the upper end of this range.

Although southern Ontario is a hot spot of nuclear ${ }^{14} \mathrm{CO}_{2}$ emissions, the improvements achieved by incorporating the CNSC emission data is apparent and the level of agreement of the annual averages is quite promising. When including auxiliary tracers, such as $\mathrm{CO}$ or black carbon, future studies to infer $\mathrm{FFCO}_{2}$ fluxes appear to be viable. The transport model errors will then have to be addressed quantitatively by comparing different high-resolution transport models, which will also help to quantify the transport model uncertainty for different temporal aggregations. The long-term 
perspective could be a network of multiple sites in this region that provides ${ }^{14} \mathrm{CO}_{2}$ observations for a high-resolution inversion framework that allows to simultaneously estimate the release of ${ }^{14} \mathrm{CO}_{2}$ by the nuclear industry and the regional $\mathrm{FFCO}_{2}$ emissions.

\section{ACKNOWLEDGMENTS}

The authors would like to thank Robert Kessler, MicheleErnst, and Lauriant Giroux for their diligent care and efforts for the ${ }^{14} \mathrm{CO}_{2}$ sampling program of Environment Canada. We would especially like to thank Bernd Kromer and the staff of the ${ }^{14} \mathrm{C}$ laboratory in Heidelberg for their careful work analyzing the ${ }^{14} \mathrm{CO}_{2}$ samples. We also thank 2 anonymous reviewers for their comments and suggestions that helped to improve our manuscript. This work was supported by the Environment Canada Clean Air Regulatory Agenda (CARA) and funding received by FRV through a Visiting Fellowship to the Canadian Government Laboratories Award by the National Science and Engineering

\section{Research Council of Canada (NSERC).}

\section{REFERENCES}

Andres RJ, Boden TA, Breon FM, Ciais P, Davis S, Erickson D, Gregg JS, Jacobs on A, Marland A, Miller J, Oda T, Olivier JGJ, Raupach MR, Rayner P, Treanton K. 2012. A synthesis of carbon dioxide emissions from fossil-fuel combustion. Biogesciences 9:1845- 71 .

Beninson D, Gonzalez AJ. 1982. Application of the dose limitation system to the control of ${ }^{14} \mathrm{C}$ releases from heavy-water-moderated reactors. IAEA-SM-258/53.

Dias C, Santos R, Stenström K, Nicoli I, Skog G, da Silveira Corrêa R. 2008. ${ }^{14} \mathrm{C}$ content in vegetation in the vicinities of Brazilian nuclear power reactors. Journal

of Environmental Radioactivity 99(7):1095-101.

Emission Database for Global Atmospheric Research [EDGAR]. Release version 4.1 of the European Commission, Joint Research Centre (JRC)/Netherlands Environmental Assessment Agency (PBL). Available from http://edgar.jrc.ec.europa.eu. Accessed 10 January 2011.

Gerbig C, Lin JC, Wofsy SC, Daube BC, Andrews AE, Stephens BB, Bakwin PS, Grainger CA. 2003. Toward constraining regional-scale fluxes of $\mathrm{CO}_{2}$ with atmospheric observations over a continent: 1 . Observed spatial variability from airborne platforms. Journal of Geophysical Research: Atmospheres 108:4756, doi: 10.1029/2002JD003018.

Guan D, Liu Z, Geng Y, Lindner S, Hubacek K. 2012. The gigatonne gap in China's carbon dioxide inventories. Nature Climate Change 2(9):672-5.

Graven HD, Gruber N. 2011. Continental-scale enrichment of atmospheric ${ }^{14} \mathrm{CO}_{2}$ from the nuclear power industry: potential impact on the estimation of fossil fuel-derived $\mathrm{CO}_{2}$. Atmospheric Chemistry and Physics 11:12,339-49.

Graven HD, Guilderson TP, Keeling RF. 2012. Observations of radiocarbon $\mathrm{CO}_{2}$ at seven global sampling sites in the Scripps flask network: analysis of spatial gradients and seasonal cycles. Journal of Geophysical Research 117: D02303, doi:10.1029/2011JD016535.

Hesshaimer V, Levin I. 2000. Revision of the stratospheric bomb ${ }^{14} \mathrm{CO}_{2}$ inventory. Journal of Geophysical Research 105(D9):11,641-58.

Holton JR, Haynes PH, McIntyre ME, Douglass AR, Rood BR, Pfister L. 1995. Stratosphere-troposphere exchange. Reviews of Geophysics 33(4):403-39.

Hsueh DY, Krakauer NY, Randerson JT, Xu X, Trumbore SE, Southon JR. 2007. Regional patterns of radiocarbon and fossil fuel-derived $\mathrm{CO}_{2}$ in surface air across North America. Geophysical Research Letters 34: L02816, doi:10.1029/2006GL027032.

Kromer B, Münnich KO. 1992. $\mathrm{CO}_{2}$ gas proportional counting in Radiocarbon dating-review and perspective. In: Taylor RE, Long A, Kra RS, editors. Radiocarbon After Four Decades. New York: Springer-Verlag. p 184-97.

Levin I, Münnich KO, Weiss W. 1980. The effect of anthropogenic $\mathrm{CO}_{2}$ and ${ }^{14} \mathrm{C}$ sources on the distribution of ${ }^{14} \mathrm{CO}_{2}$ in the atmosphere. Radiocarbon 22(2):37991.

Levin I, Naegler T, Kromer B, Diehl M, Francey RJ, Gomez-Pelaez AJ, Steele LP, Wagenbach D, Weller R, Worthy DEJ. 2010. Observations and modelling of the global distribution and long-term trend of atmospheric ${ }^{14} \mathrm{CO}_{2}$. Tellus B 62:26-46.

Levin I, Kromer B, Schmidt M, Sartorius H. 2003. A novel approach for independent budgeting of fossil fuel $\mathrm{CO}_{2}$ over Europe by ${ }^{14} \mathrm{CO}_{2}$ observations. Geophysical Research Letters 30:2194, doi:10.1029/ 2003 GL018477. 
Levin I, Rödenbeck C. 2008. Can the envisaged reductions of fossil fuel $\mathrm{CO}_{2}$ emissions be detected by atmospheric observations? Naturwissenschaften 95(3): 203-8.

Lin JC, Gerbig C, Wofsy SC, Andrews AE, Daube BC, Davis KJ, Grainger CA. 2003. A near-field tool for simulating the upstream influence of atmospheric observations: the Stochastic Time-Inverted Lagrangian Transport (STILT) model. Journal of Geophysical Research (Atmospheres) 108:4493, doi:10.1029/2002JD003161.

Marland G, Hamal K, Jonas M. 2009. How uncertain are estimates of $\mathrm{CO}_{2}$ emissions? Journal of Industrial Ecology 13:4-7.

Miller JB, Lehman SJ, Montzka SA, Sweeney C, Miller BR, Wolak C, Dlugokencky EJ, Southon JR, Turnbull JC, Tans PP. 2012. Linking emissions of fossil fuel $\mathrm{CO}_{2}$ and other anthropogenic trace gases using atmospheric ${ }^{14} \mathrm{CO}_{2}$. Journal of Geophysical Research 117: D08302, doi:10.1029/2011JD017048.

Naegler T, Levin I. 2009. Biosphere-atmosphere gross carbon exchange flux and the $\square^{13} \mathrm{CO}_{2}$ and $\square^{14} \mathrm{CO}_{2}$ disequilibria constrained by the biospheric excess radiocarbon inventory. Journal of Geophysical Research 114: D17303, doi:10.1029/2008JD011116.

Naegler T, Ciais P, Rodgers K, Levin I. 2006. Excess radiocarbon constraints on air-sea gas exchange and the uptake of $\mathrm{CO}_{2}$ by the oceans. Geophysical Research Letters 33: L11802, doi:10.1029/2005GL025408.

NassarR, Napier-Linton L, Gurney KR, Andres RJ, Oda T, Vogel FR, Deng F. 2012. Improving the temporal and spatial distribution of $\mathrm{CO}_{2}$ emissions from global fossil fuel emission datasets. Journal of Geophysical Research: Atmospheres 118:917-33.

Peylin P, Houweling S, Krol MC, Karstens U, Pieterse G, Ciais P, Heimann M. 2011. Importance of fossil fuel emission uncertainties over Europe for $\mathrm{CO} 2$ modeling: model intercomparison. Atmospheric Chemistry and Physics 11(13):6607-22.

Rasch PJ, Tie X, Boville BA, Williams on DL. 1994. A three-dimensional transport model for the middle atmosphere. Journal of Geophysical Research 99(D1): 999-1017.

Radiological Environmental Assessment Program [REMP]. 2012. Available from http://www.opg.com/ news/reports/. Accessed 21 January 2012.

Roberts on JAL. 1978. The CANDU reactor system: an appropriate technology. Science 199(4329):657-64.

[StatsCan] Statistics Canada, Government of Canada. 2008. Census 2006 (Internet; cited 2011 October 4). Available from http://www40.statcan.gc.ca/. Stuiver M, Polach HA. 1977. Discussion: reporting of ${ }^{14} \mathrm{C}$ data. Radiocarbon 19(3):355-63.

Sweeney CE, Gloor E, Jacobson AR, Key RM, McKinley G, Sarmiento JL, Wanninkhof R. 2007.
Constraining global air-sea gas exchange for $\mathrm{CO}_{2}$ with recent bomb ${ }^{14} \mathrm{C}$ measurements. Global Biogeochemical Cycles 21: GB2015, doi:10.1029/2006GB002784.

Trumbore SE. 2000. Age of soil organic matter and soil respiration: radiocarbon constraints on belowground $\mathrm{C}$ dynamics. Ecological Applications 10(2):399-411.

Trumbore S. 2006. Carbon respired by terrestrial ecosystems - recent progress and challenges. Global Change Biology 12:141-53.

Turnbull JC, Miller JB, Lehman SJ, Tans PP, Sparks RJ, Southon J. 2006. Comparis on of ${ }^{14} \mathrm{CO}_{2}, \mathrm{CO}$, and $\mathrm{SF}_{6}$ as tracers for recently added fossil fuel $\mathrm{CO}_{2}$ in the atmosphere and implications for biological $\mathrm{CO}_{2}$ exchange. Geophysical Research Letters 33: L01817, doi:10.1029/2005GL024213.

Turnbull JC, Miller JB, Lehman SJ, Hurst D, Peters W, Tans PP, Southon J, Montzka SA, Elkins JW, Mondeel DJ, Romashkin PA, Elansky N, Skorokhod A. 2009a. Spatial distribution of ${ }^{14} \mathrm{CO}_{2}$ across Eurasia: measurements from the TROICA-8 expedition. Atmospheric Chemistry and Physics 9(1):175-87.

Turnbull J, Rayner P, Miller JB, Naegler T, Ciais P, Cozic A. 2009b. On the use of ${ }^{14} \mathrm{CO}_{2}$ as a tracer for fossil fuel $\mathrm{CO}_{2}$ : quantifying uncertainties using an atmospheric transport model. Journal of Geophysical Research 114: D22302, doi:10.1029/2009JD012308.

United Nations Scientific Committee on the Effects of Atomic Radiation [UNSCEAR]. 1988, 1993, 2000. Sources and effects of ionizing radiation, UNSCEA R 1988, 1993, 2000 Report to the General Assembly. Vienna: UNSCEAR.

Vogel FR, Hammer S, Steinhof A, Kromer B, Levin I. 2010. Implication of weekly and diurnal ${ }^{14} \mathrm{C}$ calibration on hourly estimates of CO-based fossil fuel $\mathrm{CO}_{2}$ at a moderately polluted site in southwestem Germany. Tellus B 62:512-20.

Vogel FR, Ishizawa M, Chan E, Chan D, Hammer S, Levin I, Worthy DEJ. 2012. Regional non- $\mathrm{CO}_{2}$ greenhouse gas fluxes inferred from atmospheric measurements in Ontario, Canada. Journal of Integrative Environmental Sciences 9(Supplement 1):41-55.

Wanninkhof R. 1992. Relationship between wind speed and gas exchange over the ocean. Journal of Geophysical Research 97(C5):7373-82.

Weiss R, Nisbet E. 2010. Top-down versus bottom-up. Science 328(5983):1241-43. 